\title{
Background Risk Information to Assist in Risk Management Decision Making
}

\author{
J. S. Hammonds \\ F. O. Hoffman \\ R. K. White \\ D. B. Miller
}

Environmental Restoration Program

P.O. Box 2003

Oak Ridge, Tennessee 37831-7298

Date Issued-October 1992

Prepared by

Environmental Sciences Division

Oak Ridge National Laboratory

Oak Ridge, Tennessee 37831

Prepared for

U.S. Department of Energy

Office of Environmental Restoration and Waste Management under budget and reporting code EW 20

MARTIN MARIETTA ENERGY SYSTEMS, INC.

managing the

Oak Ridge K-25 Site

Oak Ridge Y-12 Plant

Oak Ridge National Laboratory

under contract DE-AC05-84OR21400
Paducah Gaseous Diffusion Plant Portsmouth Gaseous Diffusion Plant under contract DE-AC05-76OR00001

for the

U.S. DEPARTMENT OF ENERGY

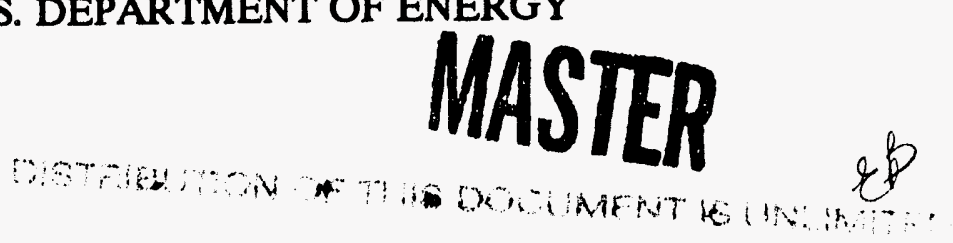




\section{CONTENTS}

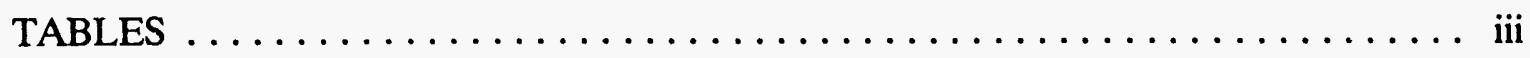

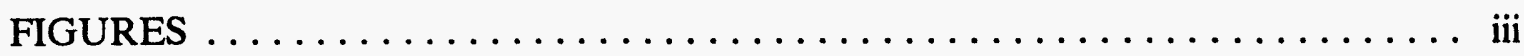

EXECUTTVE SUMMARY $\ldots \ldots \ldots \ldots \ldots \ldots \ldots \ldots \ldots \ldots \ldots \ldots \ldots \ldots$ iv

1. INTRODUCTION $\ldots \ldots \ldots \ldots \ldots \ldots \ldots \ldots \ldots \ldots \ldots \ldots \ldots \ldots \ldots \ldots$

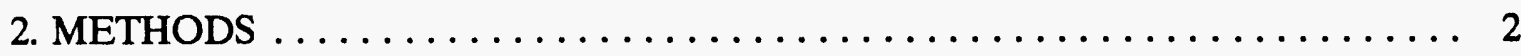

3. RESULTS AND DISCUSSION $\ldots \ldots \ldots \ldots \ldots \ldots \ldots \ldots \ldots \ldots \ldots \ldots \ldots \ldots \ldots \ldots$

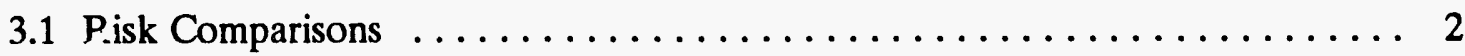

3.2 Verifiable versus Estimated but Nonverifiable Risks ............. 3

4. SUMMARY AND CONCLUSION $\ldots \ldots \ldots \ldots \ldots \ldots \ldots \ldots \ldots \ldots \ldots$

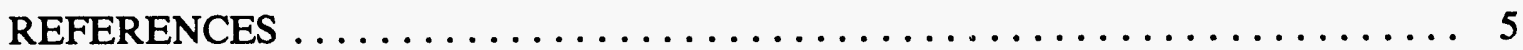




\section{TABLES}

1. Common risks often considered voluntary activities $\ldots \ldots \ldots \ldots \ldots \ldots \ldots$

2. Various reported risks encountered involuntarily $\ldots \ldots \ldots \ldots \ldots \ldots \ldots \ldots$

3. Life-time risks from background contamination $\ldots \ldots \ldots \ldots \ldots \ldots \ldots \ldots \ldots$

4. Risks from inhalation of indoor radon in Kingston and Harriman, Tennessee . . . . 9

\section{FIGURES}

1. A representation of excess risk involved with various activities in which the risk

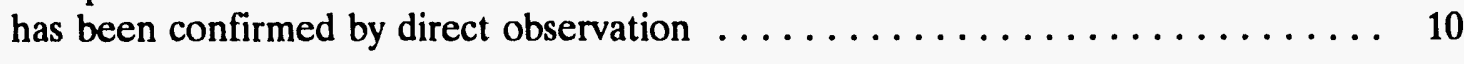

2. Nonverifiable risks determined by mathematical extrapolation to low doses that are received from interaction with the environment $\ldots \ldots \ldots \ldots \ldots \ldots$ 


\section{EXECUTTVE SUMMARY}

To provide a frame of reference for interpreting health risks from exposure to chemical and radioactive substances found at hazardous waste sites, it is helpful to identify the relative magnitude of risks of both voluntary and involuntary exposure to naturally occurring chemicals and radioactive materials. It is also useful to evaluate information about the average risks associated with familiar, everyday activities. This information provides a basis for understanding risk information that may be presented as part of the process of evaluating hazardous waste site contamination.

Three categories of risk data can be identified: (1) verifiable risks often associated with voluntary activities, (2) commonly reported risks encountered involuntarily, and (3) risks from chemicals and radionuclides in east Tennessee that are not associated with Department of Energy Oak Ridge operations. For comparison's sake, it is best to use local or regional data when possible; local or regional data can more accurately reflect site-specific conditions.

To foster an understanding of the risk information being presented, it is necessary to have a frame of reference for interpreting the magnitude and relative importance of those risks. Clarifying the difference between statistically verifiable data and data that can be estimated but not verified is an important component of this frame of reference.

Although risks taken voluntarily do not compare directly to the health risks from contaminants at hazardous waste sites, having a clearer picture of the risks associated with familiar activities helps provide perspective in evaluating health risk results associated with remediation of specific contaminants. 


\section{INTRODUCTION}

The evaluation of the need for remedial activities at hazardous waste sites requires quantification of risks of adverse health effects to humans and the ecosystem resulting from the presence of chemical and radioactive substances at these sites. The health risks from exposure to these substances are in addition to risks encountered because of the virtually unavoidable exposure to naturally occurring chemicals and radioactive materials that are present in air, water, soil, building materials, and food products. To provide a frame of reference for interpreting risks quantified for hazardous waste sites, it is useful to identify the relative magnitude of risks of both a voluntary and involuntary nature that are ubiquitous throughout east Tennessee.

Risks can be defined or quantified in a variety of ways but are usually expressed as a probability of adverse effects that are associated with exposure to the contaminants (Cohrssen and Covello 1989). For investigations conducted under the Environmental Protection Agency's Comprehensive Environmental Response, Compensation, and Liability Act risk assessment guidance, risks are defined as the probability of human health hazards resulting from environmental exposure to chemicals and radionuclides that originate directly or indirectly from human activities at a hazardous waste site (Zimmerman 1990). For carcinogens, these probabilities are expressed as excess cancer incidence over a human lifetime, which is the probability of an individual having one case of cancer above the normal background cancer rate observed in the general population. The current lifetime risk of getting cancer per individual varies between $3 \times 10^{-1}$ and $4 \times 10^{-1}$ (NCI 1988). The following table provides an explanation of scientific notation.

\begin{tabular}{cc}
\hline Actual number & Scientific notation \\
\hline $1 / 10$ & $1 \times 10^{-1}$ or $1 \mathrm{E}-1$ \\
$1 / 100$ & $1 \times 10^{-2}$ or $1 \mathrm{E}-2$ \\
$1 / 1,000$ & $1 \times 10^{-3}$ or $1 \mathrm{E}-3$ \\
$1 / 10,000$ & $1 \times 10^{-4}$ or $1 \mathrm{E}-4$ \\
$1 / 100,000$ & $1 \times 10^{-5}$ or $1 \mathrm{E}-5$ \\
$1 / 1,000,000$ & $1 \times 10^{-6}$ or $1 \mathrm{E}-6$ \\
$1 / 10,000,000$ & $1 \times 10^{-7}$ or $1 \mathrm{E}-7$ \\
$1 / 100,000,000$ & $1 \times 10^{-8}$ or $1 \mathrm{E}-8$ \\
$1 / 1,000,000,000$ & $1 \times 10^{-9}$ or $1 \mathrm{E}-9$ \\
\hline
\end{tabular}

When cancer risks exceed the background rate by a relatively large incremental fraction, they can be statistically verified through epidemiological investigation. However, when excess cancer risks are small fractions of background, it is essentially impossible to verify the 
presence of additional risk through scientific study. This is because small incremental risks are masked by stochastic fluctuations in the background rate of cancer. Therefore, at low levels of exposure, cancer risks are quantified using mathematical extrapolations based on animal or human data obtained at much higher levels. At low exposure levels, the assumption is made that a linear relationship exists between the magnitude of cancer risk and the magnitude of exposure. Although the presence of a threshold exposure level below which the risk is zero cannot be categorically denied, it is currently common practice to assume that such a threshold does not exist. In these situations, the quantification of risk is an estimate that is not statistically verifiable. There is a real probability that the true but unknown risk may even be zero.

In addition to discussing risks from the ubiquitous presence of background carcinogens in the east Tennessee environment, this report also presents risks resulting from common, everyday activities. Such information should not be used to discount or trivialize risks from hazardous waste contamination, but rather, to create a sensitivity to general risk issues, thus providing a context for better interpretation of risk information. This paper is not intended to defend or refute regulatory definitions of the acceptability of exposure to contaminants; rather the purpose of this paper is to present facts about the average risks associated with everyday activities that are familiar to the reader and to provide a basis for understanding risk information that may be presented in the process of evaluating contamination at hazardous waste sites.

\section{METHODS}

Data on commonly reported risks and background contaminant risks were collected from existing data bases and past studies. When possible, local or regional data were chosen to better reflect site-specific conditions. In some cases, only concentration data were available and risks were calculated. In other cases risk numbers were reported and used. In cases where risks for an activity were reported as an annual value, lifetime risks were derived assuming an average number of years of participation in the activity over a 70 -year average individual lifetime. Risks calculated from radiation measurements were converted to risk using the weighted risk conversion of 0.07 risk/Sv (ICRP 1991). Tables 1-4 list the data, risk calculations, and sources of information for this study. A method to present statistically verifiable and nonverifiable risk estimates is demonstrated in Figs. 1 and 2, respectively. These figures use a relative sc le to represent quantitative estimates of risk, allowing the reader to weigh the risks visually and mentally.

\section{RESULTS AND DISCUSSION}

Tables 1-4 list the concentration and risk data that were collected. Three categories of data were identified: (1) verifiable risks often associated with voluntary activities, (2) commonly reported risks encountered involuntarily (e.g., natural disasters), and (3) risks from chemicals and radionuclides in east Tennessee that are not associated with Oak 
Ridge/Department of Energy (DOE) operations. The radionuclide risk estimates are entirely based on the exposure to natural sources.

\subsection{Risk Comparisons}

Interpretation of the data presented in Tables 1-4 is useful for a perspective on risks at DOE sites in east Tennessee. Data in Table 1 represent common risks that are often considered voluntary activities. These are risks that an individual takes voluntarily and, therefore, are not directly comparable to the kinds of risks associated with inadvertent exposure to contaminants released from hazardous waste sites. The voluntary risks can be modified by adopting a more or less cautious life style.

Risks associated with inadvertent exposure to contaminants from hazardous wastes cannot be compared directly to voluntary activities such as riding a motorcycle or smoking a cigarette (Table 1). Nonetheless, knowledge that we live in a society where risks (often times high risks) are taken daily can be useful to illustrate that we are constantly involved in weighing risks and benefits of different activities to establish and maintain our quality of life.

Table 2 lists commonly reported risks of an involuntary nature. These are risks resulting from natural disasters and accidents. These risks can also be adjusted depending on choice of residence and life style. For the most part, however, they are not completely avoidable if one lives in a location where such disasters can occur. With the exception of the risk estimates from a meteorite strike and from sharing a room with a smoker, which are mathematically extrapolated values, the involuntary risks presented in Table 2 are statistically verifiable risks (i.e., they can be confirmed by direct observation). Selected data from Tables 1 and 2 are summarized in Fig. 1.

Tables 3 and 4 and Fig. 2 show risks from background contamination that is present in east Tennessee. Exposure to these contaminants may be modified to some degree, but for the most part they are not completely avoidable because the presence of these risks is not common knowledge. In addition, the risk estimates associated with this background contamination are not verifiable; rather they are derived using various animal data to mathematically extrapolate to regions of low dose. Some of these nonverifiable risks that are encountered daily include cosmic radiation, indoor radon, terrestrial gamma rays that are naturally occurring in the materials present on earth, air pollution, and various chemicals with which man has contaminated the environment. Examples of estimated but statistically nonverifiable risks are presented in Tables 3 and 4 and Fig. 2.

Ideally, the list of background contaminants for which data are available should encompass all possible background contaminants that might be present. At this time, complete information on all background contaminants is not available. However, information of this type is useful for a comparison of hazardous waste site risks to these types of background risks.

\subsection{Verifiable versus Estimated but Nonverifiable Risks}

To understand risk results that are reported for a site, a reader must have some frame of reference or perspective on the magnitude and relative importance of risks that are being 
reported. To provide this perspective, it will be necessary to distinguish between statistically verifiable risks that are documented through direct observation (i.e., deaths from natural disaster and accidents) and virtually nonverifiable health effects that are the outcome of animal-to-human and high-to-low exposure extrapolation using mathematical models and a series of assumptions. For most carcinogenic substances, lifetime risks below $10^{-3}$ are essentially nonverifiable, because such risks cannot be detected with scientific credibility against comparatively high incidence rates of cancer in the general population resulting from all causes.

\section{SUMMARY AND CONCLUSION}

The primary purpose of this report is to provide a manner of understanding the magnitude of risks resulting from contamination at hazardous waste sites. To achieve this goal, various risk information for contaminants in east Tennessee that is not a result of specific DOE facilities and risks encountered in people's daily lives is presented. Although risks that people take voluntarily cannot be compared directly to the involuntary risks resulting from inadvertent exposure to contaminants from hazardous waste sites, they can provide an idea of how much risk one is willing to take with one's life as compared with increased levels of risk reduction associated with remediation of specific contaminants. By showing the excess risk related to familiar activities, more uncertain and unknown risks hopefully can be more effectively communicated. 


\section{REFERENCES}

Brill, A. B., S. J. Adelstein, E. L. Saenger, and E. W. Webster. 1982. Low-Level Radiation Effects: a Fact Book. Society of Nuclear Medicine, Inc., New York, New York.

Clarke, R. H. and T. R. E. Southwood. 1989. "Risks from Ionizing Radiation." Nature, Vol. 338: 197-198.

Cohrssen, J. J. and V. T. Covello. 1989. Risk Analysis: A Guide to Principles and Methods for Analyzing Health and Environmental Risks. National Technical Information Service, U. S. Department of Commerce, Springfield, Virginia. PB 89-137772.

Crouch, Edmund A. C. and Richard Wilson. 1982. Risk/Benefit Analysis. Ballinger Publishing, Cambridge, Massachusetts.

EPA (United States Environmental Protection Agency). 1991. Health Effects Assessment Summary Tables. OERR 9200.6-303(91-1). Office of Research and Development, Office of Emergency and Remedial Response, Washington, DC.

Hawthorne, A. R. et al. 1988. Indoor Air Quality in 300 Homes in Kingston/Harriman, Tennessee. ORNL-6401. Health and Safety Research Division, Oak Ridge National Laboratory, Oak Ridge, Tennessee.

ICRP (International Commission on Radiological Protection). 1991. 1990 Recommendations of the International Commission on Radiological Protection. ICRP No. 60. Vol. 21 No. 1-3. Pergamon Press.

NCI (National Cancer Institute). Division of Cancer Prevention and Control. Surveillance Program. Cancer Statistics Review 1973-1988.

NCRP (National Council on Radiation Protection and Measurements). 1987. Ionizing Radiation Exposure of the Population of the United States. Report No. 93. Bethescia, Maryland.

Slovic, P. 1986. Informing and Educating the Public About Risk. Risk Analysis 6(4): 403-415.

STORET User's Handbook. 1985. Computer Sciences Corporation, 6521 Arlington Boulevard, Falls Church, Virginia.

Zimmerman, R. 1990. Governmental Management of Environmental Risk. CRC Press Inc., Lewis Publishers, Boca Raton, Florida. 


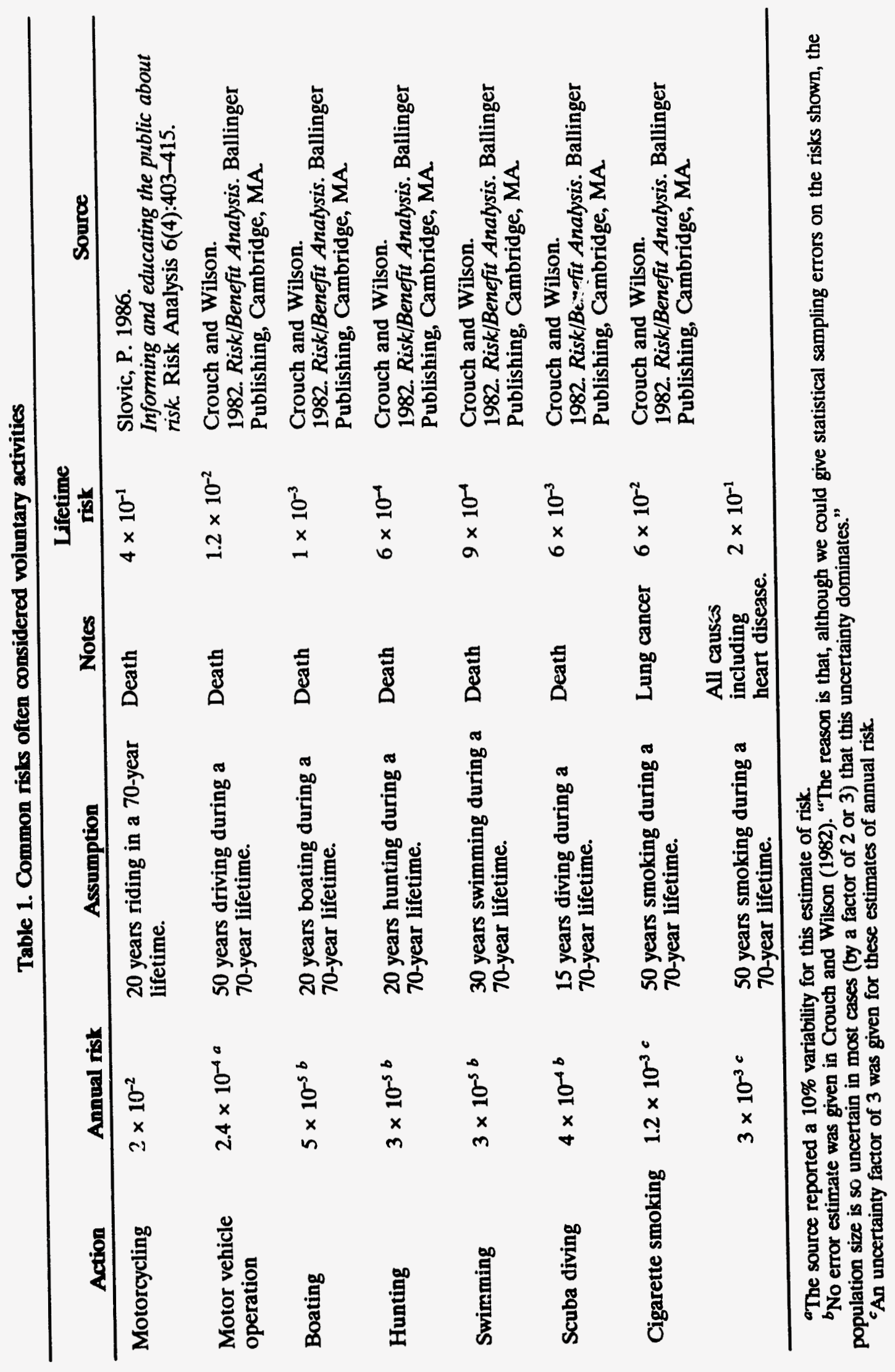




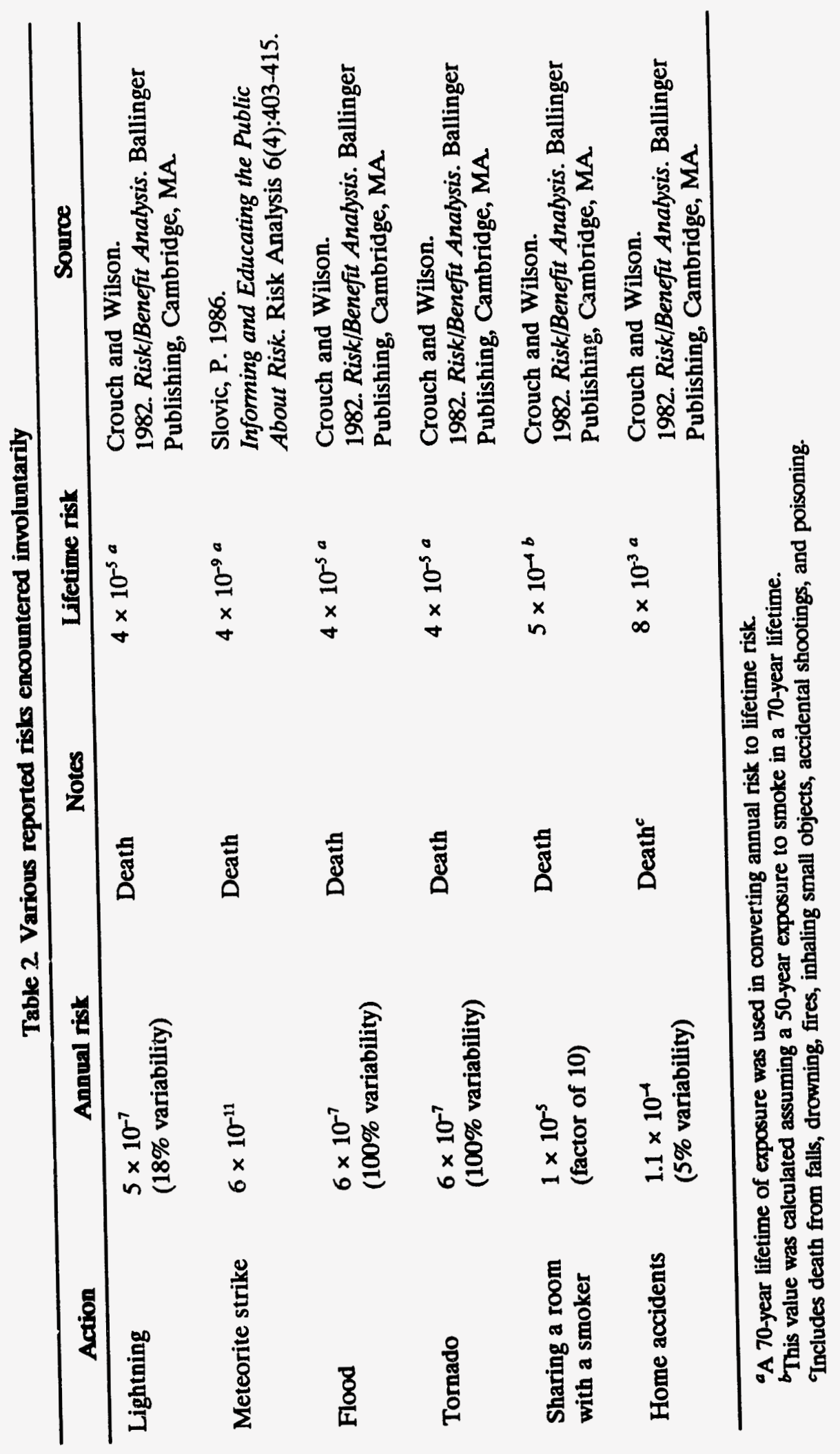




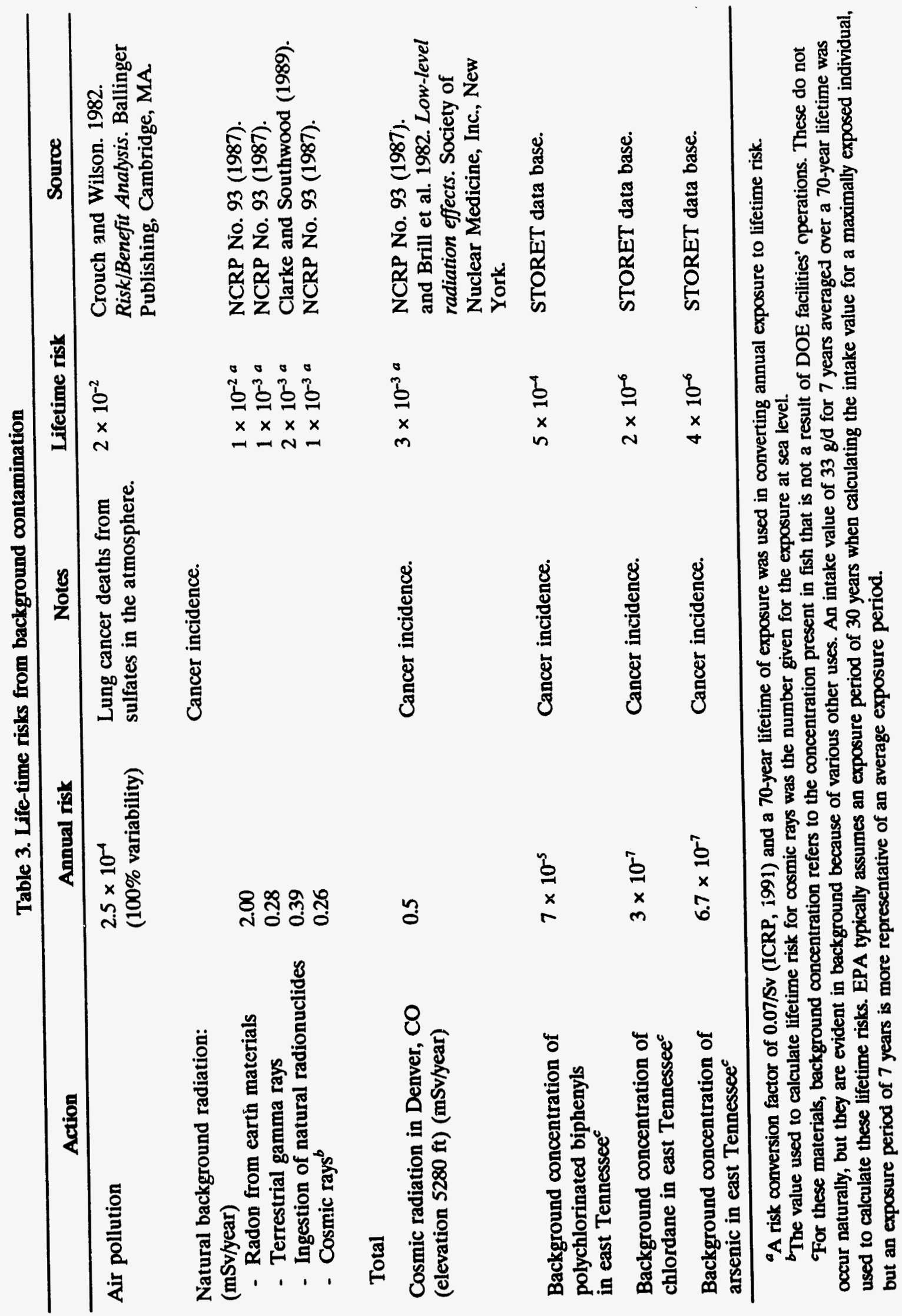


9

Table 4. Risks from inhalation of indoor radon in Kingston and Harriman, Tennessee

\begin{tabular}{|c|c|}
\hline Season & $\begin{array}{c}\text { Concentration } \\
(\mathrm{pCi} / \mathrm{L})\end{array}$ \\
\hline \multicolumn{2}{|l|}{ Winter } \\
\hline Low & 0.1 \\
\hline Mean & 2.38 \\
\hline High & 22.0 \\
\hline \multicolumn{2}{|l|}{ Summer } \\
\hline Low & 0.1 \\
\hline Mean & 1.3 \\
\hline High & 11.4 \\
\hline Annual average & $1.84^{a}$ \\
\hline Lifetime risk $^{b}$ & $1 \times 10^{-2} c$ \\
\hline \multicolumn{2}{|c|}{$\begin{array}{l}{ }^{a} \text { This concentration was determined by averaging the } \\
\text { mean concentrations occurring in the summer and winter } \\
b \text { Unit risk conversion factor of } 5.6 \times 10^{-6}\left(\mathrm{pCi} / \mathrm{m}^{3}\right)^{-1} \\
\text { from EPA (1991). } \\
{ }^{c} \text { The lifetime risk was calculated with the assumption } \\
\text { of exposure during a 70-year lifetime. } \\
\text { Source: Hawthorne et al. } 1988 \text {. }\end{array}$} \\
\hline
\end{tabular}

